\title{
Analysis and Design of a PFC AC-DC Converter with Electrical Isolation
}

\author{
Chia-Ching Lin ${ }^{*}$, Lung-Sheng Yang ${ }^{\dagger}$, and Ren-Jun Zheng* \\ ${ }^{* \dagger}$ Department of Electrical Engineering, Far East University, Tainan City, Taiwan
}

\begin{abstract}
This study presents a single-phase power factor correction AC-DC converter that operates in discontinuous conduction mode. This converter uses the pulse-width modulation technique to achieve almost unity power factor and low total harmonic distortion of input current for universal input voltage $\left(90 \mathrm{~V}_{\mathrm{rms}}\right.$ to $\left.264 \mathrm{~V}_{\mathrm{rms}}\right)$ applications. The converter has a simple structure and electrical isolation. The magnetizing-inductor energy of the transformer can be recycled to the output without an additional third winding. The steady-state analysis of voltage gain and boundary operating conditions are discussed in detail. Finally, experimental results are shown to verify the performance of the proposed converter.
\end{abstract}

Key words: DCM, PFC, PWM, THD

\section{INTRODUCTION}

DC power sources are widely used in industrial products and consumer electronics, such as battery chargers, DC power supplies, uninterruptible power supplies, inverters, and instruments. Thus, AC-DC power conversion is an important consideration. Diode-bridge or thyristor rectifiers can realize AC-DC power conversion, but such rectifiers will result in power pollution, including pulsating input current, low power factor, and high total harmonic distortion of input current $\left(\mathrm{THD}_{\mathrm{i}}\right)$. Several power factor correction (PFC) AC-DC converters have been investigated to address these issues. These converters possess non-isolated and isolated topologies. Non-isolated topologies include the boost [1]-[4], buck [5]-[7], buck-boost [8]-[10], Cuk [11], SEPIC [12], [13], and ZETA types [14]. These converters are operated in continuous conduction mode and discontinuous conduction mode (DCM) for different output-power applications. Isolated topologies include forward [15]-[17] and flyback types [18]-[20]. The forward types achieve low output voltage ripple and high $\mathrm{THD}_{\mathrm{i}}$. Nevertheless, this converter requires the third winding to recycle the magnetizing-inductor energy of the transformer. The flyback types are shown in Fig. 1(a). This converter achieves high power factor and low $\mathrm{THD}_{\mathrm{i}}$. Moreover, flyback types have a

Manuscript received Dec. 30, 2013; accepted May 3, 2014

Recommended for publication by Associate Editor Joung-Hu Park.

${ }^{\dagger}$ Corresponding Author: yanglungsheng@yahoo.com.tw

Tel: +886-6-5979566-5410, Far East University

* Dept. of Electric Eng., Far East University, Taiwan simple structure and low cost but have low efficiency because of the transformer leakage inductor. The clamping method is presented in [21], [22] to recycle leakage inductor energy. However, this method makes the power circuit complicated.

We propose a single-phase PFC AC-DC converter, as shown in Fig. 1(b). The proposed converter circuit configuration is very simple. The configuration includes only a set of input filter $L_{f}-C_{f}$, a diode-bridge rectifier, a transformer $T_{r}$, an inductor $L_{1}$, an output diode $D_{o}$, and an output capacitor $C_{o}$. The proposed converter does not have the transformer leakage inductor issue associated with the flyback converter. Moreover, transformer magnetizinginductor energy can be recycled to the output without an additional third winding. This converter is operated in DCM by using the pulse-width modulation technique to achieve high power factor and low $\mathrm{THD}_{\mathrm{i}}$ for universal input-voltage applications.

\section{OPERATING PRINCIPLES}

The equivalent circuit of the proposed converter is shown in Fig. 2. The transformer is modeled as a magnetizing inductor $L_{m}$ and an ideal transformer. Some key waveforms in a half line-source period are shown in Fig. 3. The operating principle is analyzed as $0<\omega t<\pi$, where $\omega$ is the line angular frequency, because of the symmetrical characteristics of the single-phase system.

Mode 1, $\left[k T_{s}, t_{k l}\right]: S_{1}$ is switched on. The current- flow path is shown in Fig. 4(a). The line source energy is transferred to the magnetizing inductor $L_{m}$ of the transformer and the 


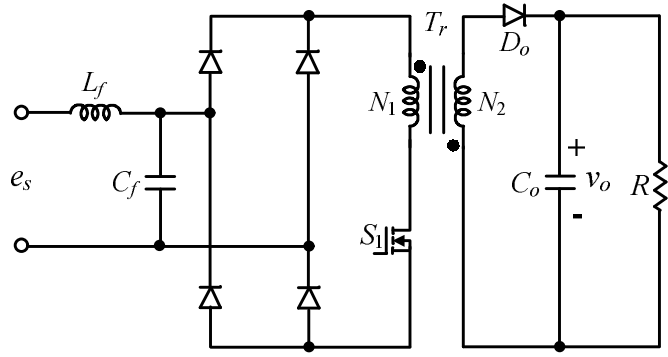

(a)

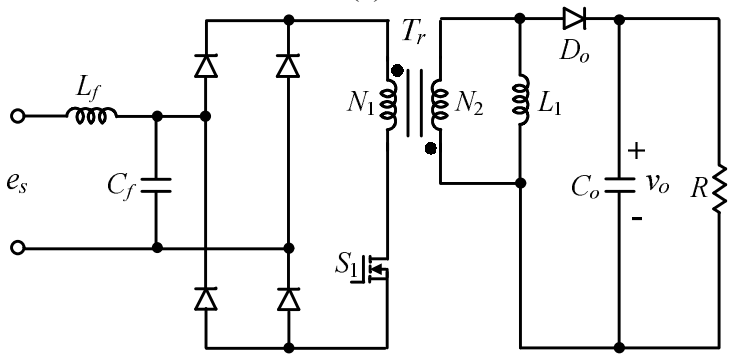

(b)

Fig. 1. (a) Conventional single-phase AC-DC flyback converter and (b) proposed single-phase $\mathrm{AC}-\mathrm{DC}$ converter.

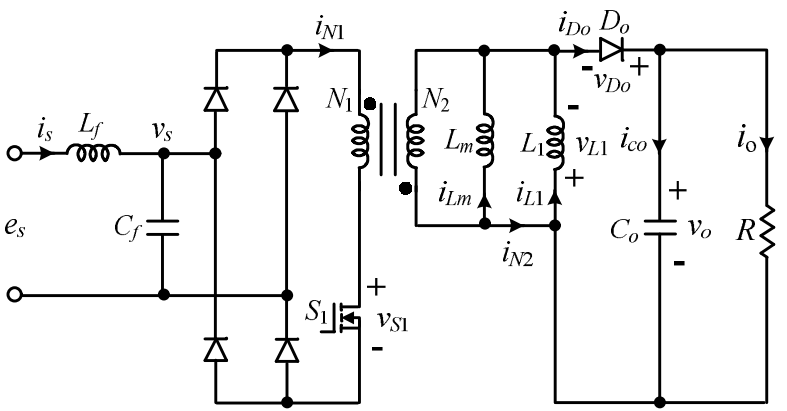

Fig. 2. Equivalent circuit of proposed converter.

inductor $L_{1}$. Thus, the currents $i_{L m}$ and $i_{L 1}$ are increased linearly. Given that magnetizing inductor $L_{m}$ is significantly larger than inductor $L_{1}$, the magnetizing-inductor current $i_{L m}$ becomes lower than inductor current $i_{L 1}$. The energy stored in magnetizing inductor $L_{m}$ is the residual magnetism of the transformer. The energy stored in output capacitor $C_{o}$ is discharged to load $R$. This mode ends when $S_{1}$ is switched off.

Mode 2, $\left[t_{k 1}, t_{k 2}\right]: S_{1}$ is switched off. The current-flow path is shown in Fig. 4(b). The energies stored in magnetizing inductor $L_{m}$ and inductor $L_{1}$ are released to output capacitor $C_{o}$ and load $R$. The currents $i_{L m}$ and $i_{L 1}$ are decreased linearly. This mode ends when the currents $i_{L m}$ and $i_{L 1}$ are equal to zero. Therefore, the transformer residual magnetism can be released to empty during each switching period.

Mode 3, $\left[t_{k 2}, \quad(k+1) T_{s}\right]: S_{1}$ remains switched off. The current-flow path is shown in Fig. 4(c). The energies stored in magnetizing inductor $L_{m}$ and inductor $L_{1}$ are empty at $t=t_{k 2}$. The energy stored in output capacitor $C_{o}$ is discharged to load $R$. This mode ends when $S_{1}$ is switched on at the beginning of the next switching period.

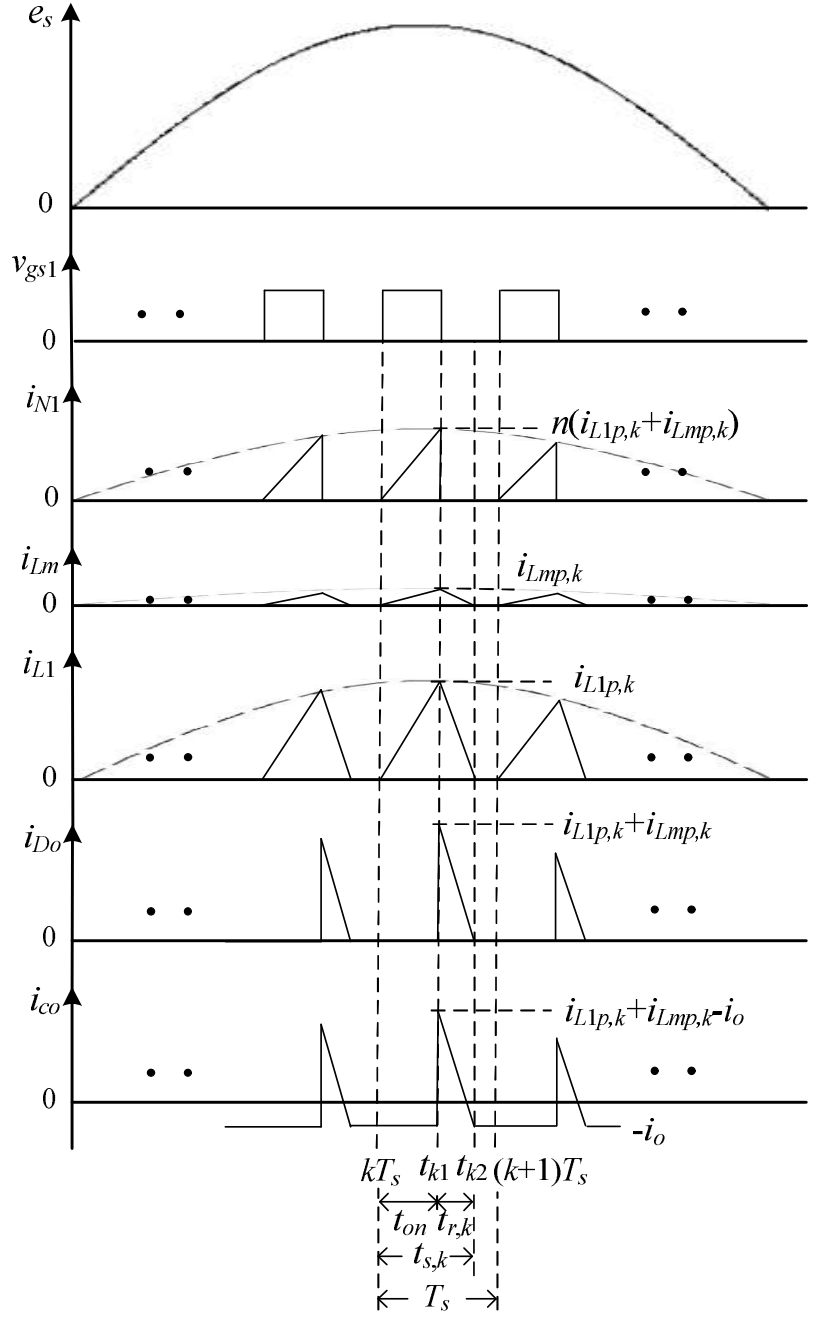

Fig. 3. Key waveforms of the proposed converter for $0<\omega t<\pi$.

\section{STEADY-STATE ANALYSIS}

Given that the single-phase system is symmetrical, the following analysis is discussed for $0<\omega t<\pi$. For simplicity, the effect of the input filter is neglected. The line voltage is given by

$$
e_{s}(t)=v_{s}(t)=\sqrt{2} V_{r m s} \sin \omega t=V_{m} \sin \omega t
$$

where $V_{r m s}$ and $V_{m}$ are the root-mean-square value and line voltage amplitude, respectively. The line voltage is considered a piecewise constant during each switching period because switching frequency $f_{s}$ is larger than line frequency $f_{1}$. If $m$ is the switching number within $[0, \pi / \omega]$, then $m$ is equal to $f_{s} / 2 f_{1}$. The following analysis is considered during switching period $\left[k T_{s},(k+1) T_{s}\right]$, where $k=0,1, \ldots ., m-1$. The magnetizing inductor $L_{m}$ is ignored in the following analysis because it is significantly larger than inductor $L_{1}$.

When $S_{1}$ switched turned on, the voltage across inductor $L_{1}$ is obtained as

$$
v_{L 1}=n \times\left|e_{s}\left(t_{k}\right)\right|
$$

where es(tk) is the input-voltage level during switching the 


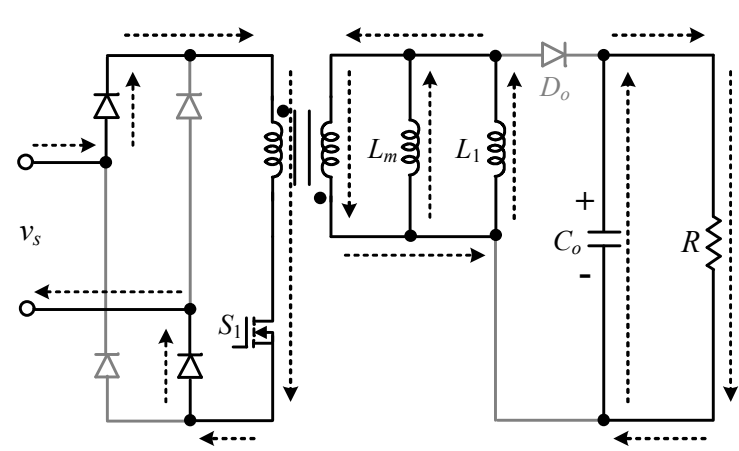

(a) Mode 1 .

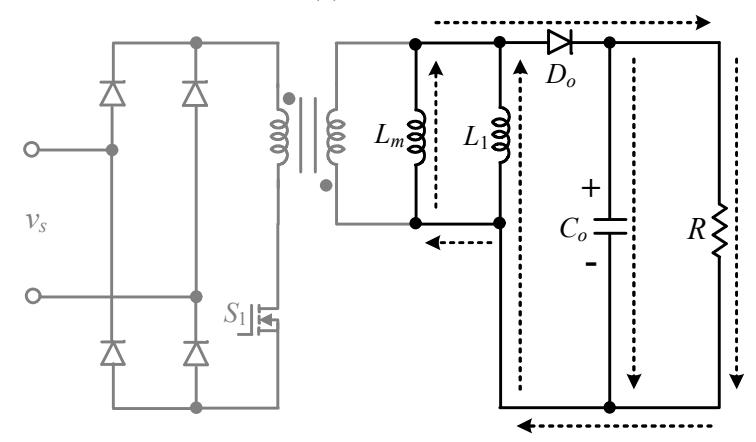

(b) Mode 2 .

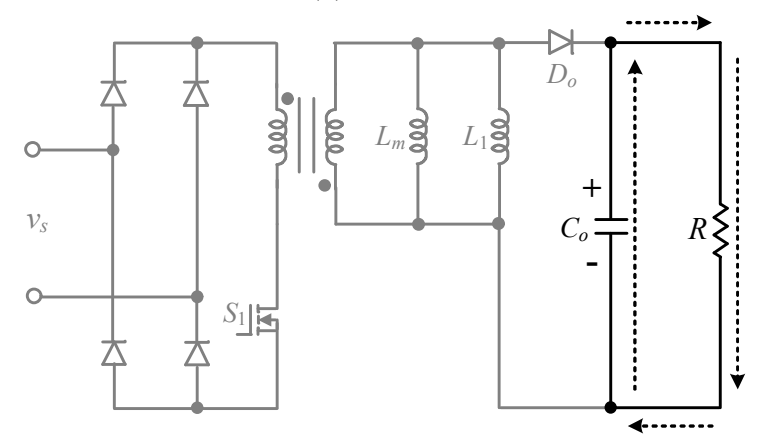

(c) Mode 3.

Fig. 4. Current flow path of the proposed converter for $0<\omega t<\pi$.

period $\left[k T_{s},(k+1) T_{s}\right]$, and the turns ratio of transformer $n=$ $N_{2} / N_{1}$. Then,

$$
\frac{d i_{L 1}(t)}{d t}=\frac{n \times\left|e_{s}\left(t_{k}\right)\right|}{L_{1}}, \quad k T_{s} \leq t \leq t_{k 1}
$$

The inductor current $i_{L 1}$ is given by

$$
i_{L 1}(t)=\frac{n \times\left|e_{s}\left(t_{k}\right)\right|}{L_{1}}\left(t-k T_{s}\right), \quad k T_{s} \leq t \leq t_{k 1}
$$

When $t$ is equal to $t_{k 1}$, the peak value of inductor current $i_{L 1}$ is

$$
i_{L 1 p, k}=\frac{n \times\left|e_{s}\left(t_{k}\right)\right|}{L_{1}} t_{o n}=\frac{n \times\left|e_{s}\left(t_{k}\right)\right|}{L_{1}} d T_{s}
$$

where $t_{o n}=t_{k 1}-k T_{s}=d T_{s}$.

When $S_{1}$ is switched off, the voltage across inductor $L_{1}$ is given by

Then,

$$
v_{L 1}=-v_{o}
$$

$$
\frac{d i_{L 1}(t)}{d t}=-\frac{v_{o}}{L_{1}}
$$

By solving (7), we derive the inductor current $i_{L 1}$ as follows:

$$
i_{L 1}(t)=-\frac{v_{o}}{L_{1}}\left(t-t_{k 1}\right)+i_{L 1 p, k}, \quad t_{k 1} \leq t \leq t_{k 2}
$$

Given that $i_{L 1}\left(t_{k 2}\right)=0$, the peak value of inductor current $i_{L 1}$ is

$$
i_{L 1 p, k}=\frac{v_{o}}{L_{1}} t_{r, k}
$$

where $t_{r, k}=t_{k 2}-t_{k 1}$.

Using (5) and (9), time duration $t_{r, k}$ can be given by

$$
t_{r, k}=\frac{n \cdot\left|e_{s}\left(t_{k}\right)\right|}{v_{o}} d T_{s}
$$

\section{A. Power Factor Correction}

As shown in Fig. 3, the average value of unfiltered input current $i_{N 1}$ in one switching period $T_{s}$ can be computed as

$$
i_{N 1, \text { avg }}(t)=\frac{t_{o n} n i_{L 1 p}}{2 T_{s}}
$$

where $i_{L 1 p}$ is the inductor current peak value for each switching period. Substituting (1) and (5) into (11), we derive the following equation:

$$
i_{N 1, \text { avg }}(t)=\frac{t_{o n} n i_{L 1 p}}{2 T_{s}}=\frac{d^{2} n^{2} T_{s} V_{m}}{2 L_{1}}|\sin \omega t|
$$

The average value of unfiltered input current $i_{N 1}$ is sinusoidal and in phase with the input voltage. Moreover, the harmonic components of current $i_{N 1}$ are distributed over the switching frequency multiples. The harmonic components are easily filtered out by using input filter $L_{f}-C_{f}$. The input filter cutoff frequency is significantly lower than the switching frequency.

\section{B. Voltage Gain}

From Fig. 3, the average value of the output-capacitor current $i_{c o}$ during $\left[k T_{s},(k+1) T_{s}\right]$ can be obtained as

$$
i_{c o, k(a v g)}=\frac{\frac{1}{2} t_{r, k} i_{L 1 p, k}-i_{o} T_{s}}{T_{s}}
$$

Substituting (1), (5), and (10) into (13) yields

$$
i_{c o, k(\text { avg })}=\frac{n^{2} d^{2} V_{m}^{2} T_{s}}{2 L_{1} v_{o}} \sin ^{2} \omega t_{k}-\frac{v_{o}}{R}
$$

The average value of output-capacitor current $i_{c o}$ during a half line-source period $[0, \pi / \omega]$ is written as follows:

$$
i_{c o, a v g}=\frac{\omega}{\pi} \sum_{k=0}^{m-1} i_{c o, k} T_{s}=\frac{\omega}{\pi} \sum_{k=0}^{m-1}\left(\frac{n^{2} d^{2} V_{m}^{2} T_{s}}{2 L_{1} v_{o}} \sin ^{2} \omega t_{k}-\frac{v_{o}}{R}\right) T_{s}
$$

Given that $m$ is larger than 1, equation (15) is approximated as:

$$
i_{c o, a v g}=\frac{\omega}{\pi} \int_{0}^{\frac{\pi}{\omega}}\left(\frac{n^{2} d^{2} V_{m}^{2} T_{s}}{2 L_{1} v_{o}} \sin ^{2} \omega t-\frac{v_{o}}{R}\right) d t=\frac{n^{2} d^{2} V_{m}^{2} T_{s}}{4 L_{1} v_{o}}-\frac{v_{o}}{R}
$$

The output voltage differential equation is given by 


$$
\frac{d}{d t} v_{o}=\frac{1}{C_{o}}\left(\frac{n^{2} d^{2} V_{m}^{2} T_{s}}{4 L_{1} v_{o}}-\frac{v_{o}}{R}\right)
$$

The DC model equation is written as

$$
\frac{n^{2} D^{2} V_{m}^{2} T_{s}}{4 L_{1} V_{o}}=\frac{n^{2} D^{2} V_{m}^{2}}{4 L_{1} f_{s} V_{o}}=\frac{V_{o}}{R}
$$

where $V_{o}$ and $D$ are the DC quantities of $v_{o}$ and $d$, respectively.

The normalized inductor time constant is then defined as

$$
\tau_{L 1} \equiv \frac{L_{1} f_{s}}{R}
$$

Substituting (19) into (18), the voltage gain is derived as

$$
M=\frac{V_{o}}{V_{m}}=\frac{n D}{2 \sqrt{\tau_{L 1}}}
$$

\section{Boundary Condition}

The current $i_{L 1}$ must be zero in each switching period to ensure that the proposed converter is operated in DCM. From Fig. 3, time duration $t_{s, k}$ is obtained as

$$
t_{s, k}=t_{o n}+t_{r, k}=\frac{D T_{s}\left(V_{o}+n \cdot\left|e_{s}\right|\right)}{V_{o}}
$$

When the maximum value of $t_{s, k}$ is equal to $T_{s}$ and $\left|e_{s}\right|$ is equal to $V_{m}$, the proposed converter is operated in boundary conduction mode. Therefore, substituting $t_{s, k}=T_{s}$ and $\left|e_{s}\right|=V_{m}$ into (21) can determine the boundary voltage gain as

$$
M_{b c}=\frac{V_{o}}{V_{m}}=\frac{n D}{1-D}
$$

Using (20) and (22), the curves of voltage gain and boundary voltage gain are shown in Fig. 5 . When the voltage gain $M$ is equal to its boundary voltage gain $M_{b c}$, the boundary normalized inductor time constant $\tau_{L 1 B}$ is given by

$$
\tau_{L 1 B}=\frac{(1-D)^{2}}{4}
$$

$\tau_{L 1 B}$ is plotted in Fig. 6. We can observe that the proposed converter is operated in DCM when $\tau_{L 1}<\tau_{L 1 B}$.

\section{SELECTIONS OF INDUCTOR AND CAPACITOR}

\section{A. Selection of Inductor $L_{1}$}

The appropriate $\tau_{L 1 B}$ is selected under the required voltage gain to ensure that the proposed converter is operated in DCM. The inductor $L_{1}$ needs to satisfy the following inequality:

$$
L_{1}<\frac{R}{f_{s}} \tau_{L 1 B}
$$

\section{B. Selection of Output Capacitor $C_{o}$}

Using (14), the average value of output-capacitor current $i_{c o}$ during one switching period is simplified as follows:

$$
i_{c o, k}=\left(\frac{n^{2} D^{2} V_{m}^{2}}{4 L_{1} f_{s} V_{o}}-\frac{V_{o}}{R}\right)-\frac{n^{2} D^{2} V_{m}^{2}}{4 L_{1} f_{s} V_{o}} \cos 2 \omega t_{k}
$$

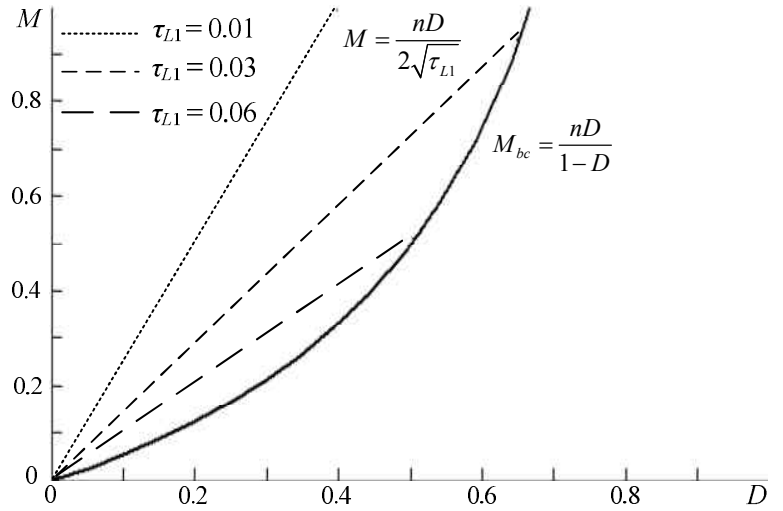

Fig. 5. Voltage gain and boundary voltage gain (under $n=0.5$ ).

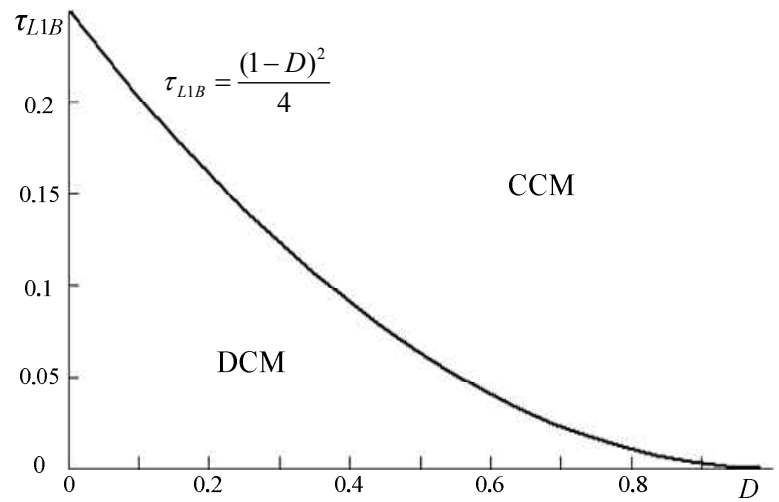

Fig. 6. Boundary operating condition.

Substituting (18) into (25), output-capacitor current $i_{c o}$ is expressed as

$$
i_{c o, k}=\frac{-n^{2} D^{2} V_{m}^{2}}{4 L_{1} f_{s} V_{o}} \cos 2 \omega t_{k}
$$

Therefore, the output voltage ripple in one switching period is given by

$$
\Delta V_{o, k}=\left(\frac{-n^{2} D^{2} V_{m}^{2}}{4 L_{1} C_{o} f_{s} V_{o}} \cos 2 \omega t_{k}\right) T_{s}
$$

Then, the output voltage ripple function during time interval $[0, \pi / \omega]$ is obtained as

$$
\Delta V_{o}(t)=\int_{0}^{t}\left(\frac{-n^{2} D^{2} V_{m}^{2}}{4 L_{1} C_{o} f_{s} V_{o}} \cos 2 \omega t^{\prime}\right) d t^{\prime}=\frac{-n^{2} D^{2} V_{m}^{2}}{4 L_{1} C_{o} f_{s} V_{o}} \times \frac{\sin 2 \omega t}{2 \omega}(28)
$$

Using (28), the output voltage ripple during time interval $[0, \pi / \omega]$ is derived as

$$
V_{o, \text { ipple }}=2\left|\Delta V_{o}(t)\right|_{\text {peak }}=\frac{n^{2} D^{2} V_{m}^{2}}{4 \omega L_{1} C_{o} f_{s} V_{o}}
$$

Thus,

$$
\frac{V_{o, \text { ripple }}}{V_{o}}=\frac{n^{2} D^{2} V_{m}^{2}}{4 \omega L_{1} C_{o} f_{s} V_{o}^{2}}=\frac{n^{2} D^{2}}{4 \omega L_{1} C_{o} f_{s} M^{2}}
$$

Output capacitor $C_{o}$ must satisfy the following inequality to meet the following output voltage ripple percentage specification: 


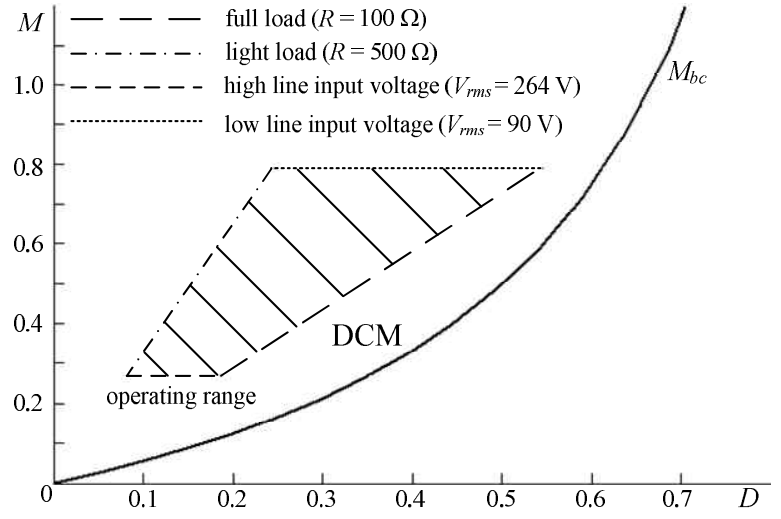

Fig. 7. Operating range of the prototype circuit.
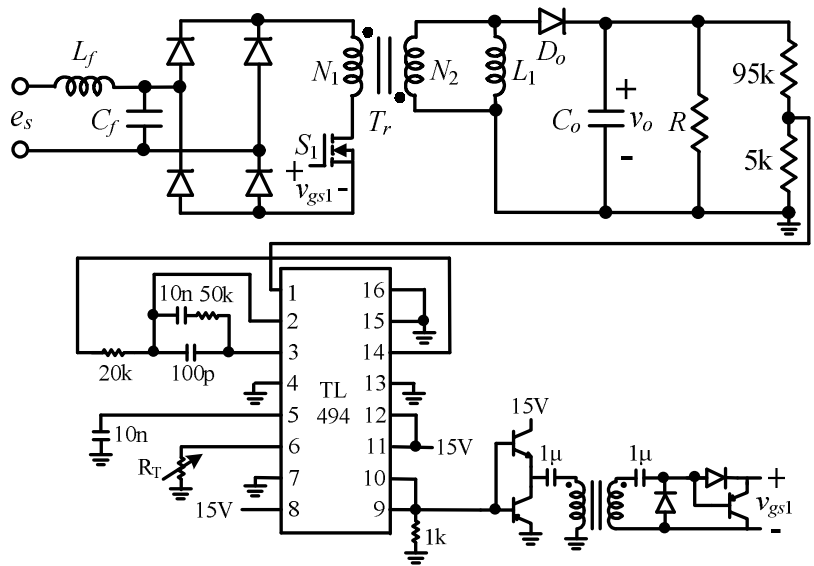

Fig. 8. Control circuit of the proposed converter.

$$
C_{o} \geq \frac{n^{2} D^{2}}{4 \omega L_{1} f_{s} M^{2}} \times \frac{V_{o}}{V_{o, \text { ripple }}}
$$

\section{EXPERIMENTAL RESULTS}

The prototype circuit is applied in the laboratory to demonstrate the performance of the proposed converter. Electrical specifications and circuit components are set as follows:

- Input voltage $V_{r m s}=90 \mathrm{~V}$ to $264 \mathrm{~V}\left(V_{m}=127 \mathrm{~V}\right.$ to $373 \mathrm{~V}$ )

- $\quad$ Output voltage $V_{o}=100 \mathrm{~V}$

- $\quad$ Line frequency $f_{1}=60 \mathrm{~Hz}$

- $\quad$ Switching frequency $f_{s}=50 \mathrm{kHz}$

- $\quad$ Output power $P_{o}=20 \mathrm{~W}$ to $100 \mathrm{~W}(R=100 \Omega$ to $500 \Omega$ )

- Transformer $T_{r}: n=0.5$ (60 turns:30 turns), core ETD $-49, L_{m}=850 \mu \mathrm{H}$

- $\quad$ Input filter $L_{f}=3.6 \mathrm{mH}$ and $C_{f}=330 \mathrm{nF}$

- $\quad$ Switch $S_{1}$ : IXFR34N80

- $\quad$ Diode $D_{o}$ : DSEC30 - 04A

The voltage gain $M$ is varied from 0.27 to 0.79 according to the electrical specifications. Substituting $M=0.79$ and $n=$

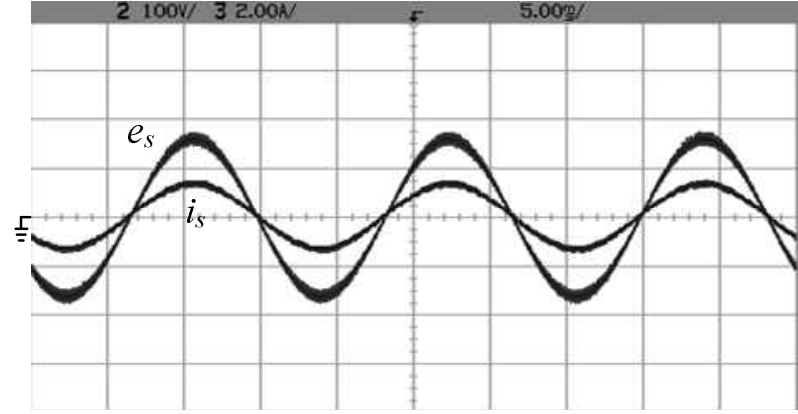

$e_{s}: 100 \mathrm{~V} / \mathrm{div}, i_{s}: 2 \mathrm{~A} / \mathrm{div}$, Time: $5 \mathrm{~ms} / \mathrm{div}$

(a)

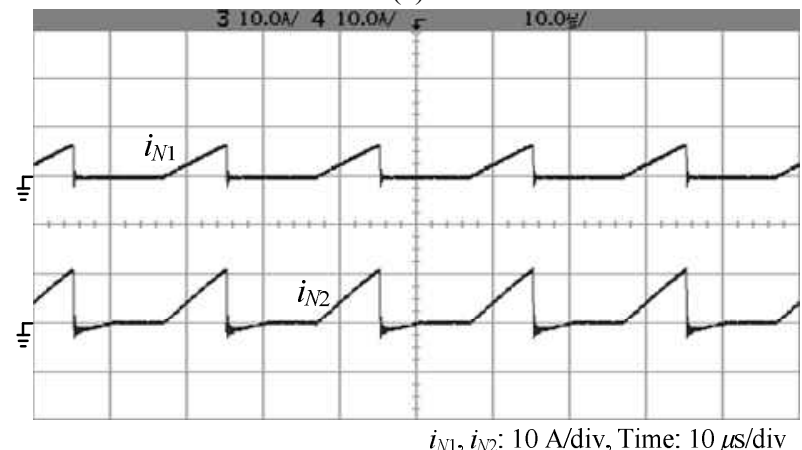

(b)

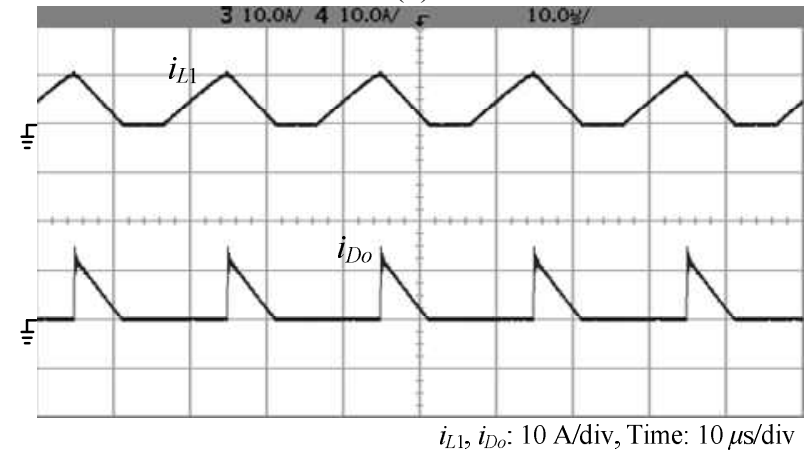

(c)

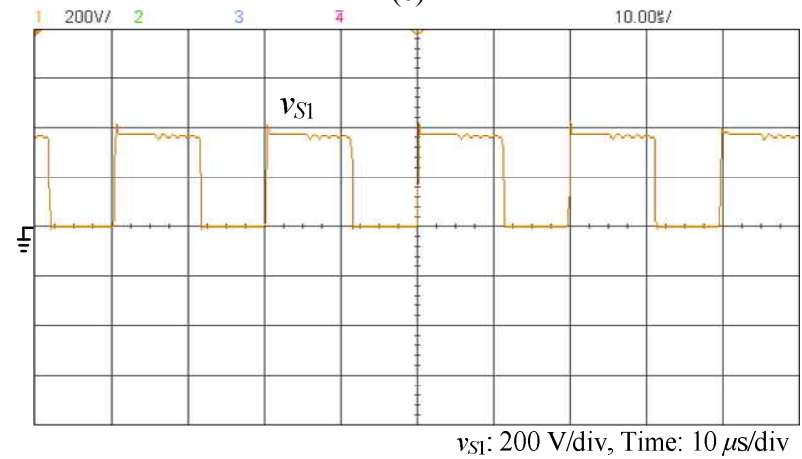

(d)

Fig. 9. Experimental waveforms at $115-\mathrm{V}_{\mathrm{rms}}$ line voltage: (a) $e_{s}$ and $i_{s}$, (b) $i_{N 1}$ and $i_{N 2}$, (c) $i_{L 1}$ and $i_{D o}$, (d) $v_{S 1}$.

0.5 into (22), the maximum duty ratio $D_{\max }$ is derived as 0.61 . Substituting $D_{\max }=0.61$ into (23), $\tau_{L 1 B}$ is obtained as 0.038 . Using (24), the inductor $L_{1}$ is given by

$$
L_{1}<\frac{R}{f_{s}} \tau_{L 1 B}=\frac{100}{50 \mathrm{k}} \times 0.038=76 \mu \mathrm{H}
$$




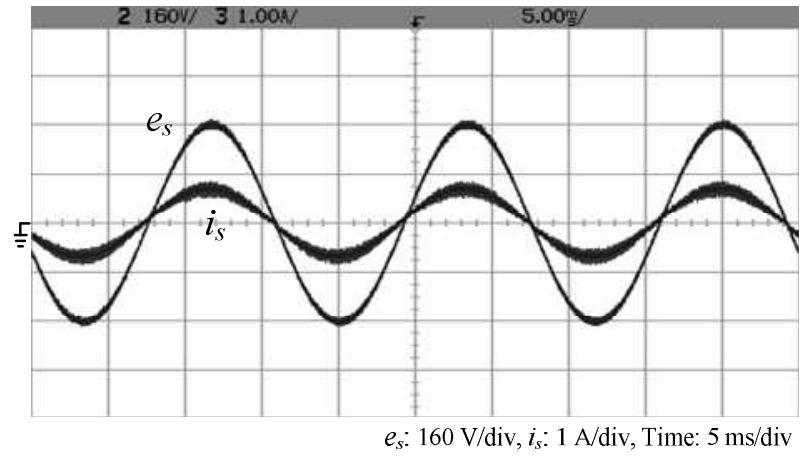

(a)

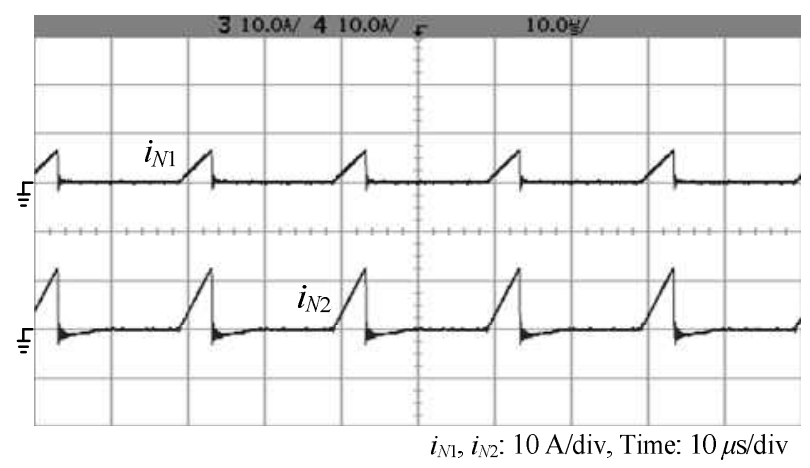

(b)

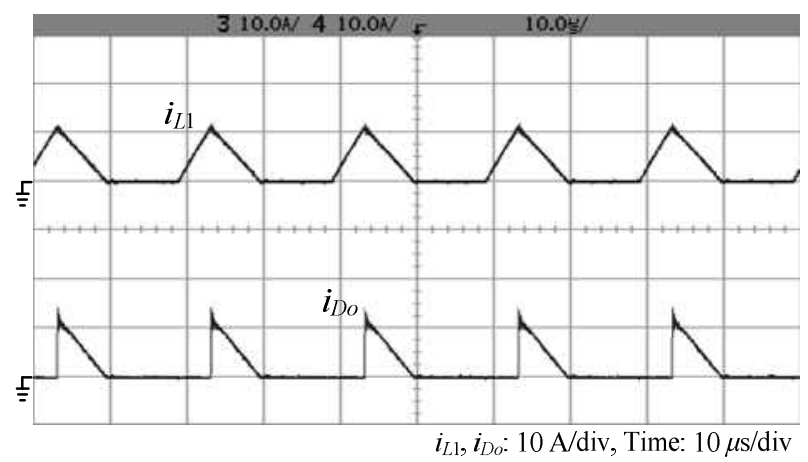

(c)

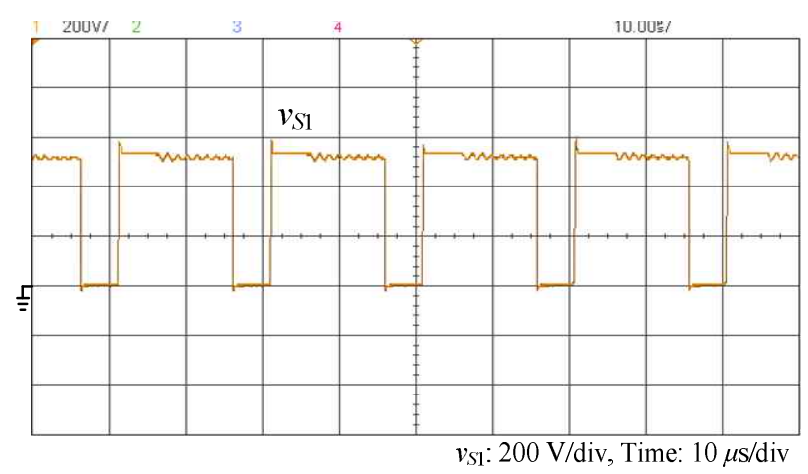

(d)

Fig. 10. Experimental waveforms at $230-\mathrm{V}_{\text {rms }}$ line voltage: (a) $e_{S}$ and $i_{s},(\mathrm{~b}) i_{N 1}$ and $i_{N 2}$, (c) $i_{L 1}$ and $i_{D o}$, (d) $v_{S 1}$

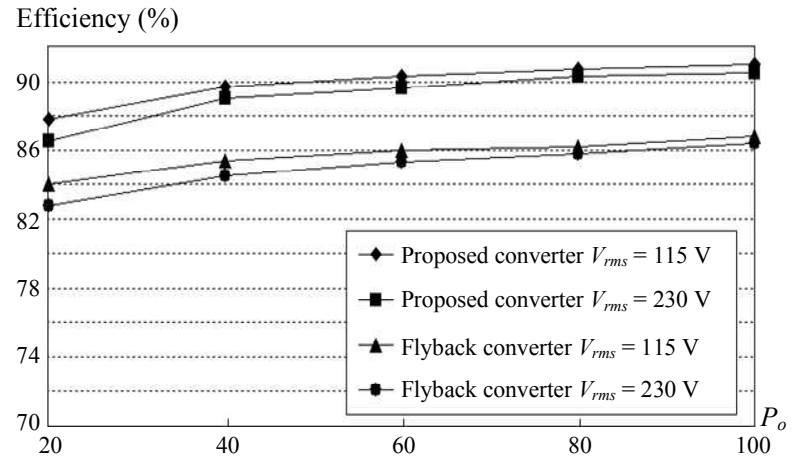

Fig. 11. Measured efficiency for the proposed converter and conventional flyback converter.

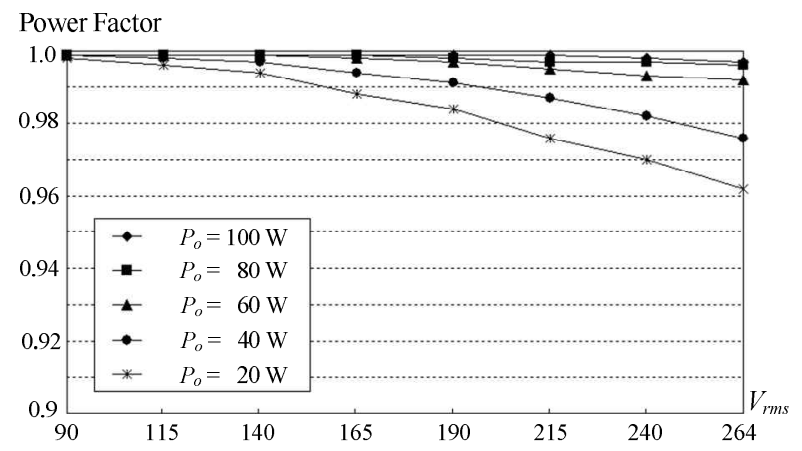

(a)

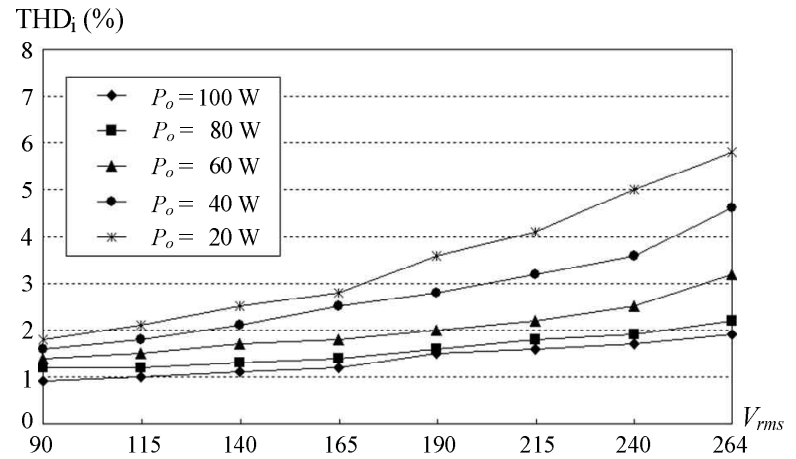

(b)

Fig. 12. Measured results: (a) power factor and (b) $\mathrm{THD}_{\mathrm{i}}$

The inductor $L_{1}$ is $60 \mu \mathrm{H}$, and the core is EI-40. Thus, $\tau_{L 1}$ is equal to 0.03 at full load $R=100 \Omega$ and is equal to 0.006 at light load $R=500 \Omega$. Substituting the two values of $\tau_{L 1}$ and $n$ $=0.5$ into (20), the operating area of the experimental prototype is shown in Fig. 7. The proposed converter is operating in DCM.

Under the operating conditions $V_{r m s}=90 \mathrm{~V}$ and $R=100 \Omega$, $M$ and $\tau_{L 1}$ are derived as 0.79 and 0.03 , respectively. Substituting $M=0.79, n=0.5$, and $\tau_{L 1}=0.03$ into (20), duty ratio $D$ is obtained as 0.55 . The ripple percentage of $V_{o}$ is selected as $5 \%$. From (31), the output capacitor inequality is given by 


$$
C_{o} \geq \frac{n^{2} D^{2}}{4 \omega L_{1} f_{s} M^{2}} \times \frac{V_{o}}{V_{o, \text { ripple }}}=536 \mu \mathrm{F}
$$

Thus, output capacitor $C_{o}$ is selected as $600 \mu \mathrm{F}$.

The control circuit is shown in Fig. 8. Figs. 9 and 10 show the experimental waveforms under $V_{r m s}=115 \mathrm{~V}, V_{o}=100 \mathrm{~V}$, $P_{o}=100 \mathrm{~W}$ and $V_{r m s}=230 \mathrm{~V}, V_{o}=100 \mathrm{~V}, P_{o}=100 \mathrm{~W}$, respectively. In Figs. 9(a) and 10(a), we observe that input current is sinusoidal and is in phase with input voltage. The current waveforms of the transformer primary and secondary sides $i_{N 1}$ and $i_{N 2}$ are shown in Figs. 9(b) and 10(b), respectively. The waveforms are taken at the peak value of input voltage. The current $i_{N 2}$ drops to zero during each switching period, which indicates that the transformer residual magnetism is released to empty during each switching period. The currents $i_{L 1}$ and $i_{D o}$ are shown in Fig. 9 (c) and 10(c), respectively. We observe that the proposed converter is operated in DCM. The waveform $v_{S 1}$ across the switch drain source is shown in Figs. 9(d) and 10(d). The measured efficiencies of the proposed converter and flyback converter are compared in Fig. 11. We observe that efficiency is improved in the proposed converter. The measured power factor and $\mathrm{THD}_{\mathrm{i}}$ are shown in Fig. 12. The measured power factor is higher than 0.96 , whereas the measured $\mathrm{THD}_{\mathrm{i}}$ is lower than $5.8 \%$.

\section{CONCLUSIONS}

The forward and flyback PFC AC-DC converters are efficient choices for electrical isolation because of their simple structure. However, the forward AC-DC converter cannot achieve high power factor and low $\mathrm{THD}_{\mathrm{i}}$. Additionally, this converter requires a third winding to recycle transformer magnetizing inductor energy. The flyback AC-DC converter can achieve high power factor and low $\mathrm{THD}_{\mathrm{i}}$. Nevertheless, the transformer leakage inductor results in low efficiency. Therefore, we present a single-phase AC-DC converter that has a simple structure and is operated in DCM to achieve high power factor and low $\mathrm{THD}_{\mathrm{i}}$. A steady-state analysis is conducted. We implement a hardware circuit with simple control logic in the laboratory. The experimental results reveal the performance of the converters. The measured efficiencies reveal that the proposed converter exhibited higher efficiency than the conventional flyback converter.

\section{ACKNOWLEDGMENT}

The authors gratefully acknowledge the financial support from the National Science Council of Taiwan under project NSC 102-2221-E-269-010.

\section{REFERENCES}

[1] F. Tahami, S. Poshtkouhi, and H. M. Ahmadian, "Piecewise affine control design for power factor correction rectifiers," Journal of Power Electronics, Vol. 11, No. 3, pp. 327-334,
May 2011.

[2] K. Yao, X. Ruan, X. Mao, and Z. Ye, "Reducing storage capacitor of a DCM boost PFC converter," IEEE Trans. Power Electron., Vol. 27, No. 1, pp. 151-160, Jan. 2012.

[3] J. M. Wang, S. T. Wu, Y. Jiang, and H. J. Chiu, "A dual-mode controller for the boost PFC converter," IEEE Trans. Ind. Electron., Vol. 58, No. 1, pp. 369-372, Jan. 2011.

[4] Y. C. Kimy, L. Jin, J. Lee, and J. Choi, "Direct digital control of single-phase AC/DC PWM converter system," Journal of Power Electronics, Vol. 10, No. 5, pp. 518-527, Sep. 2010.

[5] J. M. Alonso, M. A. D. Costa, and C. Ordiz, "Integrated buck-flyback converter as a high-power-factor off-line power supply," IEEE Trans. Ind. Electron., Vol. 55, No. 3, pp. 1090-1100, Mar. 2008.

[6] R. Itoh, K. Ishizaka, H. Oishi, and H. Okada, "Single-phase buck rectifier employing voltage-reversal circuit for sinusoidal input current waveshaping," IEE Electr. Power Appl., Vol. 146, No. 6, pp. 707-712, Nov. 1999.

[7] Y. Jang and M. M. Jovanovic, 'Bridgeless high-power-factor buck converter," IEEE Trans. Power Electron., Vol. 26, No. 2, pp. 602-611, Feb. 2011.

[8] H. L. Cheng, Y. C. Hsieh, and C. S. Lin, "A novel single stage high-power-factor $\mathrm{AC} / \mathrm{DC}$ converter featuring high circuit efficiency," IEEE Trans. Ind. Electron., Vol. 58, No. 2, pp. 524-532, Feb. 2011.

[9] G. K. Andersen and F. Blaabjerg, "Current programmed control of a single-phase two-switch buck-boost power factor correction circuit,“IEEE Trans. Ind. Electron., Vol. 53, No. 1, pp. 263-271, Feb. 2006.

[10] J. M. Alonso, J. Vina, D. G. Vaquero, G. Martinez, and R. Osorio, "Analysis and design of the integrated double buck-boost converter as a high-power-factor driver for power-LED lamps,“ IEEE Trans. Ind. Electron., Vol. 59, No. 4, pp. 1689-1697, Apr. 2012.

[11] A. A. Fardoun, E. H. Ismail, A. J. Sabzali, and M. A. Al-Saffar, "New efficient bridgeless Cuk rectifiers for PFC applications," IEEE Trans. Power Electron., Vol. 27, No. 7, pp. 3292-3301, Jul. 2012.

[12] E. H. Ismail, "Bridgeless SEPIC rectifier with unity power factor and reduced conduction losses," IEEE Trans. Ind. Electron., Vol. 56, No. 4, pp. 1147-1157, Apr. 2009.

[13] M. Mahdavi and H. Farzanehfard, "Bridgeless SEPIC PFC rectifier with reduced components and conduction losses," IEEE Trans. Ind. Electron., Vol. 58, No. 9, pp. 4153-4160, Sep. 2011.

[14] H. Zhang, Y. Zhang, and X. Ma, "Distortion behavior analysis of general pulse-width modulated zeta PFC converter operating in continuous conduction mode," IEEE Trans. Power Electron., Vol. 27, No. 10, pp. 4212-4223, Oct. 2012.

[15] L. K. Chang and H. F. Liu, "A novel forward AC/DC converter with input current shaping and fast output voltage regulation via reset winding," IEEE Trans. Ind. Electron., Vol. 52, No. 1, pp. 125-131, Feb. 2005.

[16] M. Nagao, "A novel one-stage forward-type power factor correction circuit," IEEE Trans. Power Electron., Vol. 15, No. 1, pp. 103-110, Jan. 2000.

[17] M. Daniele, P. K. Jain, and G. Joos, "A single-stage power factor corrected AC/DC converter," IEEE Trans. Power Electron., Vol. 14, No. 6, pp. 1046-1055, Nov. 1999.

[18] B. Singh and G. D. Chaturvedi, "Analysis, design and development of a single switch Flyback buck-boost AC-DC converter for low power battery charging applications," Journal of Power Electronics, Vol. 7, No. 4, pp. 318-327, 2007. 
[19] J. Zhang, D. D. C. Lu, and T. Sun, "Flyback-based single stage power-factor-correction scheme with time-multiplexing control," IEEE Trans. Ind. Electron., Vol. 57, No. 3, pp. 1041-1049, Mar. 2010.

[20] A. Lazaro, A. Barrado, M. Sanz, V. Salas, and E. Olias, "New power factor correction AC-DC converter with reduced storage capacitor voltage," IEEE Trans. Ind. Electron., Vol. 54, No. 1, pp. 384-397, Feb. 2007.

[21] K. W. Siu and Y. S. Lee, "A novel high-efficiency flyback power-factor-correction circuit with regenerative clamping and soft switching," IEEE Trans. Circuits Syst. I, Fundam. Theory Appl., Vol. 47, No. 3, pp. 350-356, Mar. 2000.

[22] N. P. Papanikolaou and E. C. Tatakis, "Active voltage clamp in flyback converters operating in CCM mode under wide load variation," IEEE Trans. Ind. Electron., Vol. 51, No. 3, pp. 632-640, Jun. 2004.

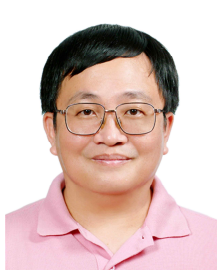

Chia-Ching Lin was born in Taiwan, R.O.C., in 1959. He graduated from the Department of Electrical Engineering, Far East University, in 1980. He received his M.S. degree in Electrical Engineering from National Cheng-Kung University in 2006. He is currently with the Department of Electrical Engineering, Far East University, Tainan, where he is an Assistant Professor. His research interests are power factor correction and dc-dc converters.

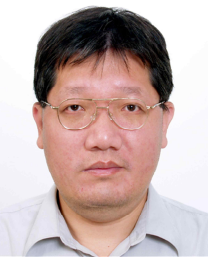

Lung-Sheng Yang was born in Taiwan, R.O.C., in 1967. He received his B.S. degree in Electrical Engineering from National Taiwan Institute of Technology, Taiwan, his M.S. degree in Electrical Engineering from National Tsing-Hua University, Taiwan, and his Ph.D degree in Electrical Engineering from National Cheng-Kung University in 1990, 1992, and 2007, respectively. He is currently with the Department of Electrical Engineering, Far East University, Tainan, where he is an Assistant Professor. His research interests are power factor correction, dc-dc converters, renewable energy conversion, and electronic ballasts.

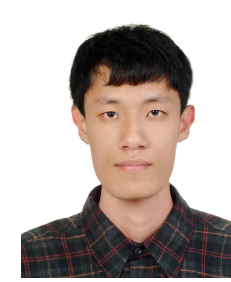

Ren-Jun Zheng was born in Taiwan, R.O.C., in 1987. He received his B.S. and M.S. degrees from the , and 2007, respectively. He is currently with the Department of Electrical Engineering, Far East University, in 2011 and 2013, respectively. His research interests include power factor correction converter and electronic ballasts. 